\title{
Developing the algorithm for assessing the competitive abilities of functional foods in marketing
}

\author{
Liudmila Nilova ${ }^{1}$, Svetlana Malyutenkova ${ }^{1, *}$ \\ ${ }^{1}$ Peter the Great St.Petersburg Polytechnic University, Institute of Industrial Management, Economics \\ and Trade, Saint-Petersburg, Russia
}

\begin{abstract}
A thorough analysis of competitive factors of functional foods has made it possible to develop an algorithm for assessing the competitive factors of functional food products, with respect to their essential consumer features - quality, safety and functionality. Questionnaires filled in by experts and the published results of surveys of consumers from different countries were used to help select the essential consumer features in functional foods. A "desirability of consumer features" model triangle, based on functional bread and bakery products, was constructed with the use of the Harrington function.
\end{abstract}

Key words: functional foods, marketing, competition, Harrington function

\section{Introduction}

Production of functional food products is now one of the popular directions of expanding the assortment of food products in most countries. This segment of the food market actively develops by expanding the share of goods that play an essential role in human's diet bread and bakery products, dairy products, beverages and other foods that are consumed daily [1-3].

At the present time, international trade of functional fermented dairy products, primarily probiotic dairy products, shows stable growth. This sector demonstrates a high level of integration between the suppliers of raw materials, manufacturers and consumers; a differentiated range of products and continuing innovations in the range of goods. Most of the market belongs to large international corporations, such as Chr. Hansen Holding A/S, Danone, Yakult Honsha Co., Ltd., Nestle, Probi AB, Danisco A/S, Lallemand Inc., and Arla Foods, Inc. [4].

Companies introduce innovative methods of interaction with customers; invest considerable funds in scientific development of more effective probiotic strains. The increase of the regional market share leads to merging and take-over of small manufacturers by bigger ones. According to the analysis, this market segment will continue to intensively develop, primarily in the Asian and Pacific regions. The growing popularity of probiotics around the world has attracted many new players to this market segment.

\footnotetext{
* Corresponding author: malutesha66@mail.ru
} 
Along with probiotic dairy products, sales of dairy products, that combine probiotics and edible plant ingredients, also demonstrate stable growth. For example, the international company "Danon", positioning itself as a manufacturer of exceptionally healthy products, is constantly expanding the range of probiotic yoghurts enriched with edible plants - fruits, cereals [3].

In the bread and bakery market, the production of functional foods is rather one-sided. Only grain additives - bran, whole grains, and multi-grain mixtures that enrich bread and bakery products with dietary fibers and vitamins that get destroyed in the process of flour production, are now widely used. Ready-made bakery mixtures are produced by both large corporations, such as "IREKS", and small companies [5]. Other directions of developing varieties of bread and bakery products, oriented for healthy nutrition, made with the use of edible plants (crushed or powdered fruit and vegetable additives) are still in the early stage of development, although some proof of their beneficial influence on the human health by enriching the human system with biologically active substances and antioxidants has already been obtained [6-9]. For example, "Fazer" produces bread with the addition of cabbage and carrots; potatoes and onions; pumpkin and apple.

The problem of mastering the production of new functional foods is quite complex. The life cycle of food products can begin only after the market-researchers have done their work - completed some market analysis, found product analogues, assessed the competitive factors of the new foods. There are different approaches to assessing the competitiveness of goods. For food products, the most appropriate definition is the ratio of the set of characteristics of the produced products to the aggregate of the requirements of the consumer to a similar product or to a set of characteristics of the products of competitors.

The unique benefits and superior value to the customer are the number one driver of new product and indicators of competitiveness of goods [10]. But in this case, Porter's five force structures cannot be neglected especially by the bargaining power of customers [11].

When assessing competitiveness of functional bread and bakery products, one must take into account that they belong to the category of essential food products that are consumed daily. Of course, one should not deceive consumer expectations. Now most consumers believe that bread should only have a traditional composition. But consumer tastes are changing. There is already a group of people who have completely stopped using bread, considering it a high-calorie and yeast-containing product. Another group of consumers believe that bread should be not only a low-calorie product, but also promote human health. At the same time most of consumers believe that, regardless of its composition, bread should be a tasty product $[12,13]$. The purpose of the work is the use of the Harrington method in the algorithm for assessing the competitiveness of functional food products for use in marketing.

\section{Data and Methods}

To develop a model of competitiveness factors of functional food products, a direct questionnaire survey was used; to reduce the dimension of many factors of competitiveness assessment, the method of peer review was used. Consistency of the opinions of experts and non-random nature of consent was assessed using the concordance coefficient, the importance of factors of competitiveness - the method of ranking factors. The Harrington method was used to construct a model for calculating the competitiveness of functional foods. 


\section{Results and discussion}

Competitiveness of food products can be assessed with the use of:

- a production panel. It is based on the demand of specific types of foods by trade companies. Disadvantages of this method - sometimes trade companies cancel their orders due to purely technical reasons, or because of subjective factors. Besides this method does not consider consumer demand for this or that product;

- a trading panel. This method is based on the trade turnover of a particular product by a trading company. The main disadvantage of this method - a chaotic layout of the goods, an inflated retail price, which leads to a decrease of the consumer demand; and different marketing ways to attract buyers (by discounts, or promotions), leading to an artificial increase of the consumer demand.

- a consumer panel, based on direct questioning of consumers. The advantage of this method - one can easily trace dynamics of goods consumption in concrete households.

In the world practice, the quantitative assessment of a food's competitive abilities consists of three stages:

1. Market analysis and selection of the most competitive sample product as a comparison base for determining the level of competitiveness of the foods;

2. Definition of the compared parameters of two food products;

3. Calculation of the integral index of competitiveness of the foods.

Selecting the right sample food to be used as a comparison base is very important. If similar foods are produced by other manufacturers, or by the same manufacturer, but according to another recipe (for example, bread enriched with bran), this product would be used as a comparison base. However, brand new functional food products, (for example, for the first time enriched with vegetable additives), most often have no analogues. Therefore, when assessing their competitiveness by pair-wise comparison, it is rather difficult to choose a sample for the comparison base. If the analogue cannot be found, one can use for comparison a traditional food product similar to the functional one, but without additives; or a functional food product of the similar composition, but with other functional additives.

Another problem lies in selecting the criteria (parameters) for the comparison base. A number of studies [12-15] have established that sensory features, along with safety and health-promotion features play an important role in purchasing functional foods. The ratio of price and quality is also of a great importance. At the same time, it is also necessary to take into account the social importance of food products that are used daily in human nutrition. Based on the analysis of advantages and disadvantages of a new functional food product in comparison with the food product used as a comparison base, a manufacturer can compile a list of criteria for assessing the product's competitive powers, i.e. consider competitiveness as a multi-factor model, including even technological factors.

To identify the factors that determine the competitiveness of functional food products, a direct questionnaire was conducted by consumers who were asked to name factors of purchase motivation and evaluate them from 0 to 10 points. To determine the significance of the production of functional food products by industrial enterprises, the survey conducted with employees of bakery enterprises. As a result, the most significant factors identified is shown in Fig. 1.

There is no need to study the impact of each factor separately. To make a quick decision, one can use the method of reducing the dimensionality of multidimensional data, which will help to reveal the correlated factors and use them as the basis to form two or three essential features of the food product. The importance of factors was determined by the method of expert assessments. For functional food products, the following factors should be chosen as essential: functionality (health-promotion), quality (organoleptic and physicochemical characteristics), and safety (depending on the edible plant additives used) 
which is formed during the production process. The final decision on the competitiveness of functional foods can be carried out by pairwise comparison or the Harrington method. As a result, the algorithm for assessing the competitive abilities of functional foods is shown in Figure 2 .

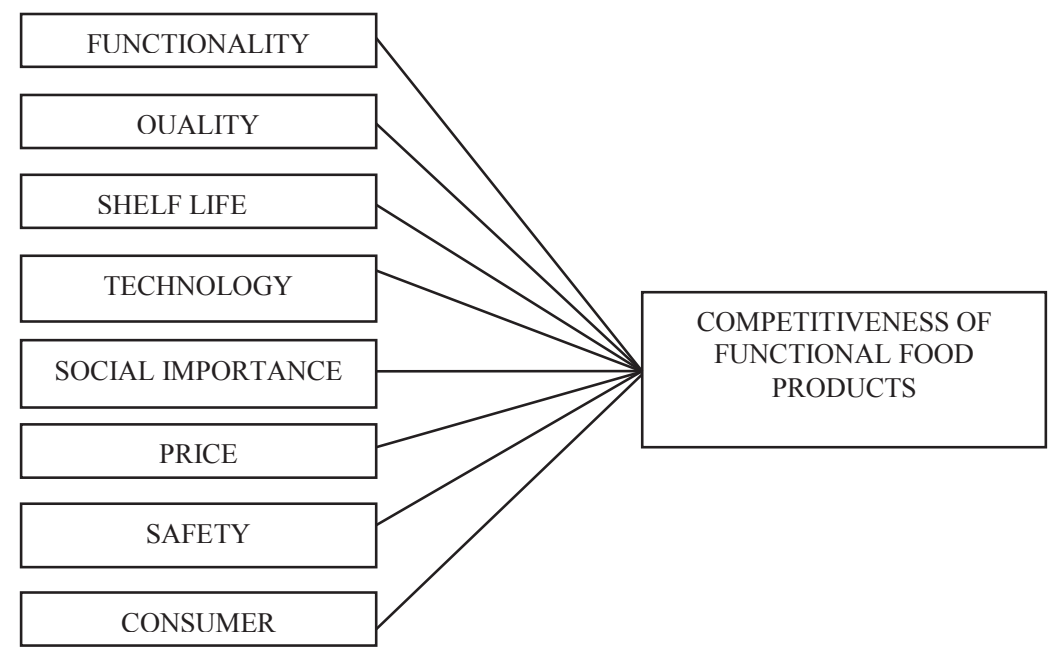

Fig. 1. Competitive factors of functional food products.

More often than not, to assess competitive powers according to the selected factors (parameters), manufacturers use the method of pair-wise comparison with a prototype (analog). But what's to be done if a functional food product can be a fundamentally new composition with new functional properties? In this case, the use of the pair-wise comparison will not result in an objective evaluation.

To obtain an objective comparative evaluation of the product's competitive powers by various factors, one can encode their natural values with the use of the Harrington desirability function. The construction of this function is based on the transformation of natural values of various qualities that characterize consumer features, into a scale of desirability preference. This helps to optimize consumer features of various foods by a variety of factors; to assess the selected consumer features by generalizing a set of properties and product characteristics into a single quantitative feature. The product displaying the greatest value of the generalized desirability function is considered the optimum.

The possibility of applying this method is considered on an example for assessing the level of competitiveness of functional bread and bakery products. Such products can be made of a variety of wheat and rye flours, with the use of different recipes, with various edible plant additives. Each of these products will have its own set of consumer features. This is why it is very difficult to select the best product among the whole lot. As objects of research we have taken bread and bakery products made of wheat flour of different yields, and enriched with cedar flour and with powdered sea buckthorn berries.

At the first stage, the assessment criteria were selected. It is very difficult to select the ultimate criterion from a variety of different ones, and give it a certain i-rank. A survey of the experts' opinions provided a good assistance. Studies that were conducted in the UK, Germany, Italy and Finland showed that most consumers of functional bread consider it as a food product that helps maintain health conditions, but is not expected to improve health. At the same time, they believe that functional ingredients should not change the sensory properties of bread [12]. Chinese consumers believe that safety of functional foods is their 
most important characteristic [14]. For bread and bakery products, safety criterion is typically associated with the use of fats containing trans fats and the formation of acrylamide during the baking process [16].

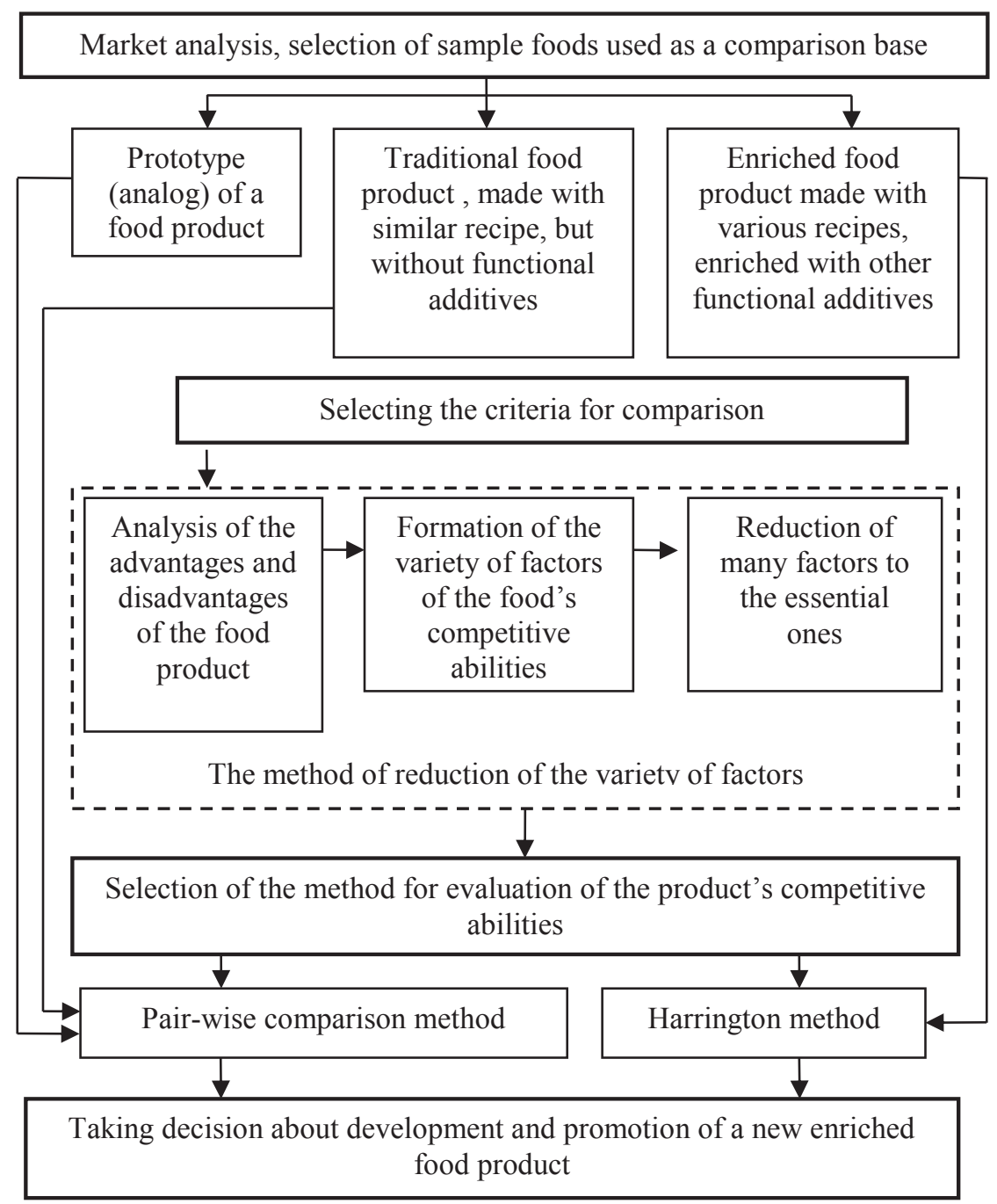

Fig. 2. Algorithm for assessing the competitive abilities of functional foods.

Based on the questionnaire filled in by experts Nilova and Malyutenkova [5] and on the consumers opinion [12-15], the authors defined the main factors for assessing the competitive powers of functional bread and bakery products - functionality, safety and organoleptic characteristics, the latter directly dependent on the physical and chemical properties of the foods. Each of the selected consumer features is complex and therefore evaluated by a range of different characteristics. The first place and - therefore - rank "1", was assigned to the most important of all properties, the last place (and rank "n") - to the least important one; the remaining characteristics were ranked from place to 2 to "n-1" (Table 1). The consistency of the experts' opinions and the non-random nature of their agreement were evaluated, respectively, by the concordance coefficient $\mathrm{C}$ according to Equation 1. The values came up to 0.93 : 


$$
C=\frac{12 S}{g^{2}\left(n^{3}-n\right)}
$$

$\mathrm{g}$ - the number of experts, $\mathrm{n}$ - the number of properties, $\mathrm{S}-$ the sum of squared deviations of all properties.

Functionality of the food product was evaluated by its capacity to supply the human body with physiologically important macro- and micronutrients; one portion containing not less than $15 \%$ of the physiologically needed human daily norm of energy and nutrients. Safety was assessed by the content of trans fats and acrylamide. The quality of the food (organoleptic and physicochemical characteristics) was evaluated according to its compliance with regulatory documents. These data, both group and individual, based on the experts' and consumers' surveys were then ranked (Table 1). The rank of the i-th index corresponded to its ordinal number when ranking the characteristics in order of decreasing importance. Since organoleptic and physico-chemical features characterize one consumer feature and are therefore equal, they were given the same rank - the average of their ordinal numbers.

To calculate the index of significance, the authors arranged a bakery product's features in a sequence from 1 to $\mathrm{n}$ in accordance with the direction of increasing the amount of all ranks assigned to it by the experts. The index of significance of each feature corresponds to the place that it occupies in the obtained row, and is calculated by Equation 2:

$$
\beta_{u}=\frac{u}{2^{u-1}}
$$

$\mathrm{u}-$ the rank assigned by the experts to this feature.

The values of $\beta_{\mathrm{u}}$ are given in Table 1 .

Table 1. The importance of competitive powers of functional bakery products.

\begin{tabular}{|c|c|c|}
\hline Consumer features & Rank, $\mathrm{u}$ & Importance indicator, $\beta_{\mathrm{u}}$ \\
\hline Safety & 1 & 1,00 \\
\hline Functionality (health-promotion) & 2 & 1,00 \\
\hline Quality: & 3 & 0,75 \\
\hline $\begin{array}{c}\text { Organoleptic characteristics } \\
\text { physical and chemical } \\
\text { characteristics }\end{array}$ & 3 & 0,75 \\
\hline
\end{tabular}

Each of the identified consumer features of the studied bread and bakery products has its own meaning and its own dimension, so they need to be converted into dimensionless figures according to the similar dimensionless scale (the Harrington desirability function) and compared with each other.

The value of the private indicator du, converted into a dimensionless desirability scale, is called private desirability. The desirability scale lies in the interval from $0(\mathrm{du}=0$, corresponding to the unacceptable level of desirability) to $1(\mathrm{du}=1$, the best desirability 
value). Each food product was thus evaluated and certain values of consumer desirability, corresponding to such categories as "very good", "good", "satisfactory", "bad", and "very bad" were attributed to it. Standard grades on the desirability scale are shown in Table 2 (columns 1, 2). They correspond to certain points on the curve, given by Equation $\mathrm{d}=\left(\mathrm{e}^{\mathrm{e}}\right)^{\mathrm{y}}$.

Table 2. Standard marks on the desirability scale.

\begin{tabular}{|c|c|}
\hline Scale of desirability & $\begin{array}{c}\text { Marks on the scale of private } \\
\text { desirability }\end{array}$ \\
\hline Very good & $1,00-0,80$ \\
\hline Good & $0,80-0,63$ \\
\hline Satisfactorily & $0,63-0,37$ \\
\hline Bad & $0,37-0,20$ \\
\hline Very bad & $0,20-0,00$ \\
\hline
\end{tabular}

Desirability values from 0 to 1 are marked on the y-axis. The values of the consumer features, rendered in a conditional scale, are indicated on the abscissa. The encoded values of consumer features of bread and bakery products are placed symmetrically to 0 on the $y$ axis (the encoded scale). Limits of the acceptable values for individual indicators can be either one-sided $\mathrm{y}_{\mathrm{n}} \leq \mathrm{y}_{\max }$ or $\mathrm{y}_{\mathrm{n}} \geq \mathrm{y}_{\min }$ (for bread and bakery products this stands for porosity, specific volume, vitamin $C$ presence, etc.) or bilateral $\mathrm{y}_{\min } \leq \mathrm{y}_{\mathrm{n}} \leq \mathrm{y}_{\max }$ (moisture percentage, acidity value, vitamin E presence, etc.).

The evaluation of quality characteristics was carried out through their specific desirabilities, established by experts. The $y_{i}$ properties of a particular food under study were compared with those proposed by the experts for each individual desirability function. After converting individual values into individual desirability functions for each characteristic of consumer features of bread and bakery products, a generalized desirability function D was calculated as the mean geometric value of the individual desirability functions adjusted to the significance of each feature according to Equation 3:

$$
D=\sqrt[n]{\Pi_{u=1}^{n}} d_{u}^{\beta}
$$

$\mathrm{n}$ - the number of features; $\beta_{\mathrm{u}}$ - the index of significance of each product's feature; $\mathrm{u}-$ the concrete feature's number in the ranked sequence.

For each group characteristics (safety, functionality, quality), the individual desirability function $\mathrm{d}_{\mathrm{u}}$ was calculated, as the mean geometric value of individual desirability indicators of the $d_{i}$ of the $i$-th individual index. These results for bakery products is shown in Table 3 .

The obtained results showed that bakery products enriched with cedar flour were characterized by greater functionality and a better quality of products, by both organoleptic and physicochemical factors. Their advantage lay in the fact that while they showed no differences in organoleptic characteristics compared to bread and bakery products made by traditional recipes, they displayed a better taste. Bakery products enriched with sea buckthorn powder had a characteristic orange color, an acidic taste, which could be improved only by adding a large amount of sugar. At the same time, the studied bread and 
bakery products showed different values of individual desirabilities, although the generalized function D, according to the desirability scale, classified them in the group of consumer features as "very good".

Table 3. Valuation of consumer properties of functional bakery products on the desirability scale.

\begin{tabular}{|c|c|c|c|c|}
\hline $\begin{array}{c}\text { Consumer } \\
\text { features/ } \\
\text { individual } \\
\text { desirability } \\
\text { function }\end{array}$ & $\begin{array}{c}\text { Bread made } \\
\text { of wheat flour } \\
\text { with the } \\
\text { addition of } \\
\text { cedar flour }\end{array}$ & $\begin{array}{c}\text { Bakery product } \\
\text { made of wheat } \\
\text { flour with the } \\
\text { addition of cedar } \\
\text { flour }\end{array}$ & $\begin{array}{c}\text { Bakery product } \\
\text { made of wheat } \\
\text { flour with the } \\
\text { addition of sea- } \\
\text { buckthorn powder }\end{array}$ & $\begin{array}{c}\text { Baked bread made } \\
\text { from wheat flour } \\
\text { with the addition } \\
\text { of sea-buckthorn } \\
\text { powder }\end{array}$ \\
\hline Safety $\left(\mathrm{d}_{1}\right)$ & 0,9219 & 0,9357 & 0,9529 & 0,0595 \\
\hline $\begin{array}{c}\text { Functionality } \\
\left(\mathrm{d}_{2}\right)\end{array}$ & 0,7327 & 0,6918 & 0,5943 & 0,6215 \\
\hline $\begin{array}{c}\text { Organoleptic } \\
\text { characteristics } \\
\left(\mathrm{d}_{3}\right)\end{array}$ & 0,9700 & 0,9800 & 0,8900 & 0,9500 \\
\hline $\begin{array}{c}\text { Physico- } \\
\text { chemical } \\
\text { characteristics } \\
\left(\mathrm{d}_{4}\right)\end{array}$ & 0,7046 & 0,7719 & 0,6566 & 0,6353 \\
\hline $\begin{array}{c}\text { Quality / }\left(\mathrm{d}_{5}\right. \\
\left(\mathrm{d}_{3} * \mathrm{~d}_{4}\right)\end{array}$ & 0,8267 & 0,8698 & 0,7644 & 0,7769 \\
\hline $\begin{array}{c}\text { The generalized } \\
\text { value of } \\
\text { individual } \\
\text { desirability } \\
\text { functions (D) }\end{array}$ & 0,8732 & 0,8791 & 0,8226 & 0,8354 \\
\hline
\end{tabular}

For a visual analysis of the "desirability" of the consumer properties of functional breads and bakery products, a comparison chart (Figure 3) is displayed, showing group complex private desirability characteristics - safety, functionality and quality, ranked from 0.5 to 1.0 on the desirability scale, which may be used in the marketing activities of any food production company.

Equation 4 (the weighted Euclidean distance) was used for a quantitative evaluation of the proximity of breads and bakery products $\mathrm{B}, \mathrm{C}, \mathrm{D}, \mathrm{E}$ to the ideal hypothetical product $\mathrm{A}$ within the obtained values of complex individual desirabilities of the group characteristics (safety, functionality, quality). The smaller the R, the closer the product stands to the ideal food.

$$
R=\sqrt{\sum_{i=1}^{n} k\left(A_{i}-P_{i}\right)}
$$

$\mathrm{R}$ - represents the distance between the products $\mathrm{A}$ and $\mathrm{P}$, and $\mathrm{P}$ represents the corresponding products $\mathrm{B}, \mathrm{C}, \mathrm{D}$ and $\mathrm{E}$;

$A_{i}$ - the complex value of the individual desirability characteristic of the group index du of the ideal product;

$P_{i}$ - the complex value of the individual desirability characteristic of the group indicator $\mathrm{du}$ of products $\mathrm{B}, \mathrm{C}, \mathrm{D}$, and $\mathrm{E}$;

$k$ - the weighting coefficient of the individual desirability characteristic of the group exponent $d_{u}$ 


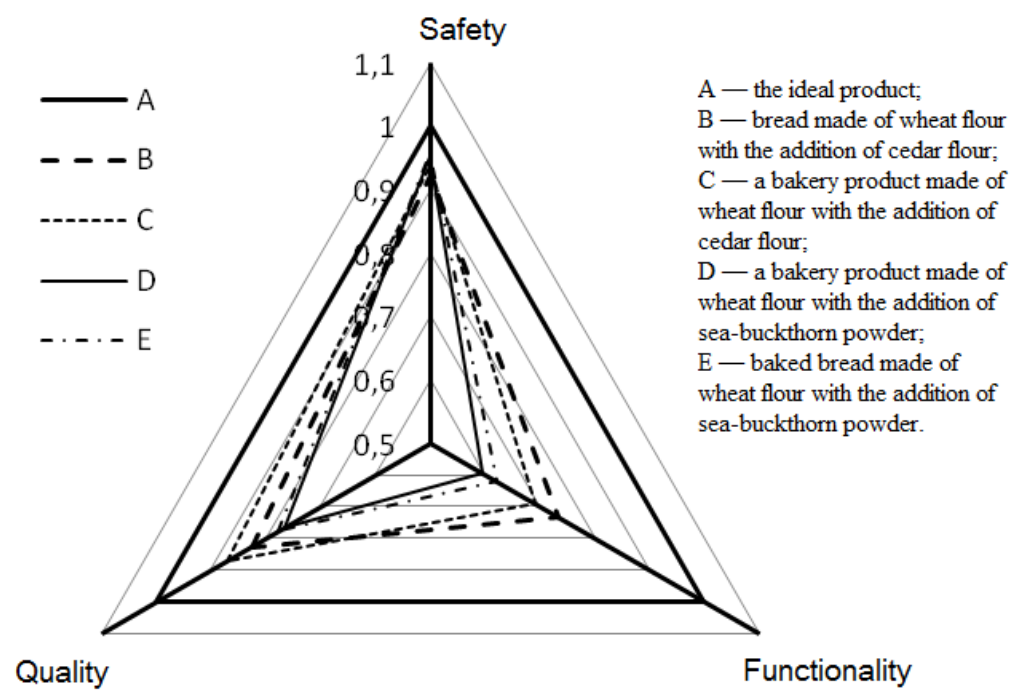

Fig. 3. Diagram of comparison "Triangle of desirability of consumer features" of functional bread and bakery products.

As a result, the following $\mathrm{R}_{\mathrm{AP}}$ values were obtained:

$\mathrm{R}_{\mathrm{AB}}=0.3043, \mathrm{R}_{\mathrm{AC}}=0.2896, \mathrm{R}_{\mathrm{AD}}=0.3917, \mathrm{R}_{\mathrm{AE}}=0.3664$. Hence it follows that in our case the bakery product made of wheat flour with the addition of cedar flour is closest to the ideal product.

\section{Conclusion}

Competitive ability of functional food products is considered as a multi-factor model, taking into account both consumer features, social significance and technological factors. Based on the analysis of the experts opinions and studies of consumer preferences in different countries, basic consumer features that play an essential role in assessing the competitive abilities of functional foods have been identified.

An algorithm for assessing competitive abilities of the foods has been developed. It uses the method of encoding important consumer features with the help of Harrington's generalized desirability function. This approach allows us to compare the consumer features of functional food products of different composition. The graphical method makes it possible to visually demonstrate the optimal consumer features of functional food products using bread and bakery products as well as the "triangle of desirability of consumer features".

\section{References}

1. Z. E. Martins, O. Pinho, I.M. Ferreira, Food industry by-products used as functional ingredients of bakery products. Trends in Food Science \& Technology Journal, 67, 106-128 (2017)

2. L.M. Beltrán-Barrientos, A. Hernández-Mendoza, M.J. Torres-Llanez, A.F. GonzálezCórdova, B. Vallejo-Córdoba, Invited review: Fermented milk as antihypertensive functional food. Journal of Dairy Science, 99, 4099-4110 (2016) 
3. F. Bimbo, A. Bonanno, G. Nocella, R. Viscecchia, G. Nardone, B. De Devitiis, D. Carlucci, Consumers' acceptance and preferences for nutrition-modified and functional dairy products: A systematic review. Appetite Journal, 113,141-154 (2017)

4. Probiotics Market Analysis and Reports. Market Analysis - Probiotics 2017, [online]: Available at: http://market-analysis.conferenceseries.com/probiotics-market-reports (2017)

5. L.P. Nilova, S.M. Malyutenkova, Innovative Foodstuff in Formation of Regional Commodity Systems. Krasnoyarsk Science Journal, 5(38), 161-174 (2016)

6. L. Nilova, O. Orlova, J. Nasonova, The role of cyclic amides in the formation of antioxidant capacity of bakery products. Agronomy Research Journal, 13(4), 1020$1030(2015)$

7. L.P. Nilova., T.V. Pilipenko, Otsenka antioksidantnykh svoystv obogashchennykh khlebobulochnykh izdeliy $\mathrm{v}$ eksperimente na laboratornykh zhivotnykh. Voprosy Pitania. Journal, 85(6), 39-47 (2016)

8. D. Dziki, R. Różyło, U. Gawlik-Dziki, M. Świeca. Current trends in the enhancement of antioxidant activity of wheat bread by the addition of plant materials rich in phenolic compounds. Trends in Food Science \& Technology, 40(1), 48-61 (2014)

9. A.A. Basov, I.M. Bykov, Voprosy Pitania, 82(3), 77-80 (2013)

10. K. B. Kahn, The PDMA handbook of new product development. 3rd ed. Hoboken, N.J.: Wiley (2013)

11. M. E. Porter, The five competitive forces that shape strategy. Special Issue on HBS Centennial, Harvard Business Review, 86(1), 78-93 (2008)

12. M. Vassallo, A. Saba, A. Arvola, M. Dean, F. Messina, M. Winkelmann, E. Claupein, L. Lähteenmäki, R. Shepherd, Willingness to use functional breads. Applying the Health Belief Model across four European countries. Appetite Journal, 52(2), 452-460 (2009)

13. T. Pohjanheimo, R. Paasovaara, H. Luomala, M. Sandell, The Customer is NOT Always Right? Marketing Orientations. Appetite Journal, 54(1), 170-180 (2010)

14. P. Yee Lee, K. Lusk, M. Mirosa, I. Oey, Effect of information on Chinese consumers' perceptions and purchase intention for beverages processed by high pressure processing, pulsed-electric field and heat treatment. Appetite Journal, 73(1), 95-104 (2014)

15. H. Rahnama, S. Rajabpour, Factors for consumer choice of dairy products in Iran, Appetite Journal, 111(1), 46-55 (2017)

16. M. Przygodzka, M.K. Piskula, K. Kukurov, Z. Ciesarov, A. Bednarikova, H. Zielinski, Analysis of the antioxidative properties and Maillard reaction products in ginger cakes enriched with rutin. Journal of Cereal Science, 65, 96-102 (2015) 